\title{
Reflux patterns and risk factors of primary varicose veins' clinical severity
}

\author{
M Garcia-Gimeno*, S Rodriguez-Camarero', S Tagarro-Villalba*, \\ E Ramalle-Gomara ${ }^{\ddagger}$ J A Ajona García ${ }^{\dagger}$ M A González Arranz*, D López García*, \\ E González-González* and C Vaquero Puerta ${ }^{\S}$ \\ ${ }^{*}$ Department of Angiology and Vascular/Endovascular Surgery, Hospital San Pedro, Logroño; ${ }^{\dagger}$ Clínica USP 'La \\ Esperanza', Vitoria; ${ }^{\ddagger}$ Department of Epidemiology, La Rioja Regional Authority, La Rioja; ${ }^{\circledR}$ Department of Angiology \\ and Vascular/Endovascular Surgery, Hospital Clínico Universitario de Valladolid, Valladolid, Spain
}

\begin{abstract}
Objectives: Primarily, to determine the association between the clinical severity of primary varicose veins and different reflux patterns in an anatomic and haemodynamic clinical study using duplex ultrasonography (DU). Secondly, to analyse the association of clinical severity with other aspects, such as risk factors for chronic venous insufficiency (CVI) and other concurrent diseases.

Method: A total of 2036 limbs were evaluated using DU. Clinical status was characterized by the CEAP (clinical, aetiological, anatomical and pathological elements) classification. The degree of clinical severity was grouped into two categories, mild to moderate $C V I\left(C_{1}-C_{3}\right)$ and severe CVI, characterized by the presence of skin changes $\left(\mathrm{C}_{4}-\mathrm{C}_{6}\right)$. We analysed the association of the different reflux patterns with CEAP status.

Results: Saphenofemoral junction (SFJ) reflux of the great saphenous vein (GSV) was associated with the most severe form of the disease (odds ratio $[\mathrm{OR}]=2.96$; confidence interval $[\mathrm{CI}] 95 \%$ : 2.2-3.8), whereas competent SFJ of the GSV with reflux from proximal veins $(\mathrm{OR}=2$; $\mathrm{CI}$ 95\%: 1.4-2.7) and the pure non-saphenous reflux $(\mathrm{OR}=4.1$; CI 95\%: 1.8-9.0) were associated with mild to moderate CVI. Obesity increased the frequency of severe CVI 2.7 times ( $\mathrm{OR}=2.7$; CI 95\%: 1.6-4.6); being a woman also increased the frequency of more severe disease 1.3 times (OR $=1.3$; CI 95\%: 1.0-1.7).

Conclusion: Anatomical and haemodynamic studies by DU are postulated as a useful diagnostic tool that allow, by identifying the pattern of venous reflux of varicose pathology, characterization of the probable association to CVI clinical severity.
\end{abstract}

Keywords: primary varicose veins; duplex ultrasonography; venous reflux point; ultrasound mapping; CEAP clinical class

\section{Introduction}

Duplex ultrasonography (DU) has been proposed as the recommended image test for the evaluation of varicose pathology. ${ }^{1-7}$ Most studies have focused on one particular aspect, such as examination of the saphenofemoral junction (SFJ) or the

Correspondence: M García Gimeno LMS PhD, Fermin

Gurbindo, 29 (26140), Lardero, La Rioja, Spain.

Email: mike170gagi@openbankmail.com

Accepted 26 October 2011 saphenopopliteal junction (SPJ) alone., ${ }^{2,3}$ We have previously published a study based on the assessment of the whole leg in patients with primary varicose veins (VVs) to show all possible patterns of reflux by a comprehensive anatomical and haemodynamic ultrasound scan mapping. ${ }^{8}$ But in addition to correctly identifying the venous reflux point, it would be necessary to know the clinical impact on patients presenting with different reflux patterns, which would facilitate and justify surgical treatment. Therefore, an aspect of great interest and the aim of this study is to determine the clinical 
severity of association of varicose pathology with reflux patterns. Clinical severity and other aspects such as risk factors and complications of chronic venous insufficiency (CVI), and other concurrent diseases are also analysed in this study.

\section{Materials and methods}

We reviewed retrospectively the ultrasound scan mapping of the lower limb venous systems for all patients referred to the private Vascular Surgery Outpatients Clinic for surgical assessment of primary VVs from January 1998 to August 2004. Patients were unselected consecutive assessments. Patients were excluded if they had a confirmed history of deep vein thrombosis in the assessed lower limb or previous venous surgery (ligation, stripping, phlebectomy or ablation). All patients had a complete physical examination and their medical history was recorded, with special focus on risk factors, complications, signs and characteristic symptoms of CVI. All duplex scan mappings were performed or supervised by a vascular surgeon with 10 years experience in the diagnostic management of CVI by DU, according to protocols and standard criteria recommended by the Spanish Society for Angiology and Vascular Surgery and previous international publications. ${ }^{10,11}$ Clinical status was assessed by means of the CEAP (clinical, aetiological, anatomical and pathological elements) classification. ${ }^{12}$ The degree of clinical severity was grouped into two categories, mild to moderate CVI $\left(C_{1}-C_{3}\right)$ and severe $C V I$, characterized by the presence of skin changes $\left(\mathrm{C}_{4}-\mathrm{C}_{6}\right)$.

DU was performed in the standing position with an Esaote-Technos MP Ultrasound scanner (Genoa, Italy) using a lineal multifrequency probe (5$10 \mathrm{MHz})$. Reflux was defined as flow in an inverse direction to physiological flow with a duration greater than 0.5 seconds after provocation manoeuvres (Valsalva, distal compression-release, and Paraná $\left.^{13}\right)$. Three sites were differentiated where reflux was evident: the groin, the popliteal fossa and the non-saphenous reflux.

\section{Reflux in the groin}

We distinguished seven reflux patterns in the groin (Figure 1): SFJ reflux of the great saphenous vein (GSV), competent SFJ of the GSV with reflux from the pelvis, competent SFJ of the GSV with reflux from the epigastric vein, SFJ reflux of the anterior accessory great saphenous vein (AAGSV), segmental reflux in AAGSV, competent SFJ of the AAGSV with reflux from the pelvis, and competent SFJ of the AAGSV with reflux from the epigastric vein. Segmental reflux in AAGSV was defined as reflux in AAGSV that does not come from SFJ reflux or competent SFJ with reflux from proximal veins and that could be justified by reflux within the AAGSV valve.

\section{Reflux in the popliteal fossa}

The possibility of reflux at the level of the SPJ through the gastrocnemius veins or through the incompetent terminal valve of the small saphenous vein (SSV) was investigated. We also investigated the possibility that the SSV would be incompetent through a refluxing Giacomini vein or through refluxing VVs from another venous system.

\section{Non-saphenous reflux}

Under the term 'non-saphenous' we included two types of VVs. First, those VVs whose reflux

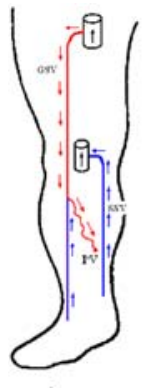

ta
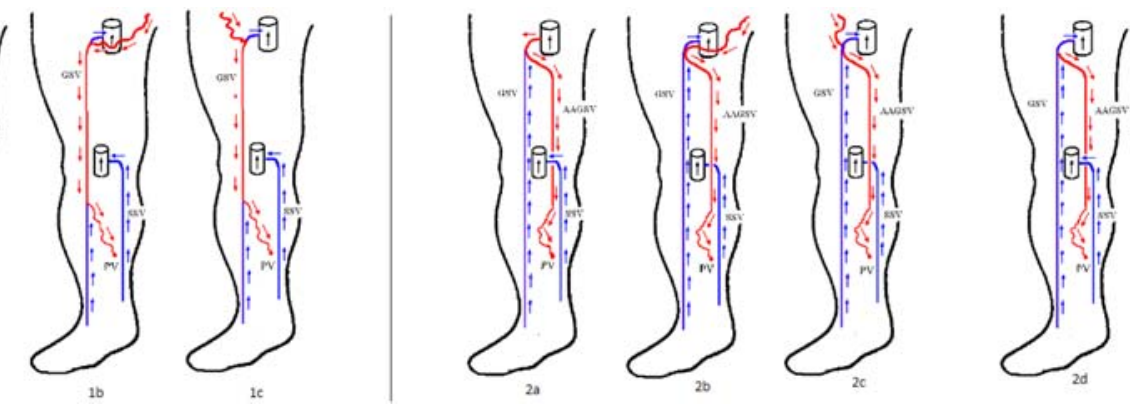

Figure 1 Reflux in the groin. (1a and 2a) Saphenofemoral junction (SFJ) reflux of great saphenous vein (GSV) and anterior accessory great saphenous vein (AAGSV). (1b and 2b) Competent SFJ with reflux from pelvis of GSV and AAGSV. (1c and 2c) Competent SFJ with reflux from epigastric veins of GSV and AAGSV. (2d) Segmental AAGSV reflux. Competence of all segments in all veins is indicated by the ascending direction of the flow (anterograde) using blue arrows, while incompetence of the vein segment assessed is indicated by the descending direction of the flow (retrograde) using red arrows. SSV, small saphenous vein; PV, perforating vein 
originated in the perforating venous (PV) system. The PVs were classified on the basis of their topography as per recommendations by the Federative International Committee on Anatomical Terminology. ${ }^{14}$ Second, we classified as pure nonsaphenous reflux those VVs whose reflux source was not related to saphenous junctions or the PV system. This type of reflux could include pelvic or epigastric reflux not afferent to saphenous junctions, with no reflux in trunk saphenous veins, and also reflux in tributaries from saphenous veins close to competent trunk saphenous veins.

\section{Anatomical category (A) of the CEAP classification}

A segment with retrograde flow may not necessarily represent the superficial venous reflux point. Many other possibilities exist, as previously described, ${ }^{8}$ and this was also considered in our study. Nevertheless, the anatomical category $\left(A_{S, D, P}\right)$ of the CEAP classification was defined, based on the presence or absence of reflux in the different segments that constitute the VVs, without any other haemodynamic consideration. ${ }^{12}$ We considered the AAGSV as a segment in our study.

We have considered that deep venous system reflux existed only if such reflux was evident in a segment different from that containing the superficial venous reflux point (for example, the SFJ or the SPJ refluxes).

The likely association between clinical severity and risk factors and concurrent diseases was analysed, in addition to the association between clinical severity and the different reflux patterns and the different segments of the anatomical category of the CEAP classification. The different patterns of reflux were analysed by only using cases where the reflux occurred in the studied pattern, to intentionally avoid the influence of a possible co-existence of a different reflux pattern.

\section{Statistical analysis}

Means and standard deviations (SDs) were calculated for quantitative variables and frequencies for qualitative findings. Bivariate analysis of association used cross-classification with Pearson's chi-squared statistics for independence of nominal variables and the chi-squared test for the trend for ordinal variables. The strength of the association between the outcome variable CEAP $\left(\mathrm{C}_{4}-\mathrm{C}_{6}\right)$ and each variable considered was assessed by means of odds ratios (ORs) and their 95\% confidence intervals (CIs). The variable with the greater number of cases was chosen as the reference category to make a more precise estimation when there was no other clinical category as a reference. In order to assess the independent association of each covariate, a logistic regression analysis was carried out with those variables that were statistically significant in the bivariate analysis. All statistical tests were performed using a two-tailed analysis. $P$ values $<0.05$ were considered to be statistically significant. Statistical analyses were conducted using the statistical package SPSS 9 (SPSS, Chicago, IL, USA).

\section{Results}

\section{Risk factors and concurrent diseases}

There were 2026 consecutive patients; of these, 431 were excluded because of recurrent VVs. Each limb was considered as a case. A total of 2036 ultrasound mappings were carried out for 1595 patients (1197 women and 398 men). The mean age of the patients included in this study was 48.2 years. The frequency of the risk factors and the assessed personal history distributed by sex are shown in Table 1. Significant statistical differences were found between these two groups for family history $(P<0.05)$ and sedentary habits $(P<0.05)$, with both variables being more frequent in women.

The history and risk factors assessed were analysed and related to the clinical severity of the CEAP classification. The results are represented in Table 2.

Obesity was the variable that presented itself as a factor that increased 2.7 times the frequency of suffering from a severe CVI (OR = 2.7; CI 95\%: 1.64.6). Female sex also resulted in a factor that increased the frequency of suffering from a more severe degree of disease by 1.3 times $(\mathrm{OR}=1.3$; CI $95 \%: 1.0-1.7)$. On the other hand, family history $(\mathrm{OR}=2.1 ; \quad \mathrm{CI} \quad 95 \%$ : 1.4-3.3), sedentary habits $(\mathrm{OR}=1.6$; $\mathrm{CI} 95 \%$ : 1.1-2.5) and previous pregnancies $(\mathrm{OR}=1.6$; $\mathrm{CI}$ 95\%: 1.1-2.0) were associated with lower degrees of clinical severity. Superficial thrombophlebitis $(\mathrm{OR}=2.4 ; \quad$ CI $95 \%: \quad 1.3-4.3)$ and a previous history of external bleeding $(\mathrm{OR}=$ 5.1; CI 95\%: 2.1-12.2) were associated with 2.4 and 5.1 times greater clinical severity phases, respectively. 
Table 1 Personal history and risk factors in the studied population distributed by gender

\begin{tabular}{|c|c|c|c|c|}
\hline Risk factors and concurrent diseases & Global (\%)* & Males $(\%)^{\dagger}$ & Females $(\%)^{\dagger}$ & $P$ value \\
\hline Family history & $540(26.5 \%)$ & $112(22.4 \%)$ & $428(27.8 \%)$ & $<0.05$ \\
\hline Obesity & $78(3.8 \%)$ & $13(2.6 \%)$ & $65(4.2 \%)$ & NS \\
\hline Sedentary habits & $363(17.8 \%)$ & $71(14.2 \%)$ & $292(19 \%)$ & $<0.05$ \\
\hline Previous pregnancy & - & - & $937(61 \%)$ & - \\
\hline Hormonal therapy & - & - & $68(4.4 \%)$ & - \\
\hline History of varicophlebitis & $68(2.8 \%)$ & $15(3 \%)$ & $43(2.8 \%)$ & NS \\
\hline History of varicose vein haemorrhage & $21(1 \%)$ & $9(1.8 \%)$ & $12(0.8 \%)$ & NS \\
\hline Haemorrhoids & $25(1.2 \%)$ & $6(1.2 \%)$ & $19(1.2 \%)$ & NS \\
\hline Gynaecological varicose vein & - & - & $9(0.6 \%)$ & - \\
\hline Varicocele & - & $7(1.4 \%)$ & - & - \\
\hline Pulmonary thromboembolism & $1(0.05 \%)$ & $1(0.2 \%)$ & 0 & NS \\
\hline Deep venous thrombosis & $9(0.4 \%)$ & $4(0.8 \%)$ & $5(0.3 \%)$ & NS \\
\hline Peripheral artery disease & $3(0.1 \%)$ & $1(0.2 \%)$ & $2(0.1 \%)$ & NS \\
\hline
\end{tabular}

NS, not statistically significant

Men $=499 /$ women $=1537$

*Representative percentage of the total cases (2036)

${ }^{\dagger}$ Representative percentage within the gender

\section{Clinical classifications}

The CEAP clinical classes were distributed as follows: $\mathrm{C}_{1}=268$ cases $(13.2 \%), \mathrm{C}_{2}=1990$ cases $(97.7 \%), \mathrm{C}_{3}=$ 264 cases $(13 \%), \mathrm{C}_{4}=239$ cases $(11.7 \%), \mathrm{C}_{5}=4$ cases $(0.2 \%)$ and $\mathrm{C}_{6}=51$ cases $(2.5 \%)$. Classes $\mathrm{C}_{1}$ and $\mathrm{C}_{2}$ were present without the presence of the rest of the clinical classes in 1543 cases (75.8\%). Symptoms related to CVI were registered in 1130 cases (55.5\%). Symptomatic patients had a 2.3 times greater probability of belonging to the more severe phase of CVI $(\mathrm{OR}=2.3$; CI 95\%: 1.7-3.0) (Table 2).

\section{Reflux pattern according to the anatomy of the CEAP classification}

The three systems: CEAP anatomical category $\left(A_{S, D, P}\right)$

The deep venous system (DVS) was also analysed. We excluded those cases exclusively caused by pelvic reflux (segment 10 of the CEAP classification). Isolated reflux from the DVS was not found because of study design. The PV system reflux was established in some segments of the superficial venous system (SVS); hence it was not found as an isolated pattern of reflux. Different

Table 2 Relationships between of risk factors, concurrent diseases, complications and symptomatology with the clinical severity from CEAP classification (bivariate analysis)

\begin{tabular}{|c|c|c|c|c|c|}
\hline Risk factors and concurrent diseases & $\operatorname{CEAP}\left(C_{1}-C_{3}\right)^{\S}$ & $\operatorname{CEAP}\left(\mathrm{C}_{4}-\mathrm{C}_{6}\right)$ & OR & $95 \% \mathrm{Cl} O \mathrm{OR}$ & $P$ value \\
\hline Prevalence & $1768(86.8 \%)^{*}$ & $268(13.2 \%)^{*}$ & & & \\
\hline Female & $1348(76.2 \%)^{\dagger}$ & $189(70 \%)^{\ddagger}$ & 1.3 & $1.01-1.78$ & $<0.05$ \\
\hline Family history & $227(15.2 \%)^{\dagger}$ & $41(7.2 \%)^{\ddagger}$ & 0.46 & $0.3-0.7$ & $<0.05$ \\
\hline Obesity & $56(3.2 \%)^{\dagger}$ & $22(8.2 \%)^{\ddagger}$ & 2.7 & $1.6-4.6$ & $<0.05$ \\
\hline Sedentary habits & $329(18.6 \%)^{\dagger}$ & $34(12.7 \%)^{\ddagger}$ & 0.6 & $0.4-0.9$ & $<0.05$ \\
\hline Previous pregnancy & $839(62.2 \%)^{\dagger}$ & $98(51.9 \%)^{\ddagger}$ & 0.6 & $0.5-0.9$ & $<0.05$ \\
\hline Hormonal therapy & $64(3.6 \%)^{\dagger}$ & $4(1.5 \%)^{\ddagger}$ & 0.4 & $0.2-1.1$ & NS \\
\hline History of varicophlebitis & $43(2.4 \%)^{\dagger}$ & $15(5.6 \%)^{\ddagger}$ & 2.4 & $1.3-4.3$ & $<0.05$ \\
\hline History of varicose vein haemorrhage & $12(0.7 \%)^{\dagger}$ & $9(3.4 \%)^{\ddagger}$ & 5.1 & $2.1-12.2$ & $<0.05$ \\
\hline Haemorrhoids & $24(1.4 \%)^{\dagger}$ & $1(0.4 \%)^{\ddagger}$ & 0.3 & $0.04-2.0$ & NS \\
\hline Gynaecological varicose vein & $9(0.5 \%)^{\dagger}$ & 0 & - & - & - \\
\hline Varicocele & $5(5.1 \%)^{\dagger}$ & $2(0.7 \%)^{\ddagger}$ & 2.7 & $0.5-13.7$ & NS \\
\hline Deep venous trombosis & $6(0.3 \%)^{\dagger}$ & $3(1.1 \%)^{\ddagger}$ & 3.3 & $0.8-13.4$ & NS \\
\hline Pulmonary thromboembolism & $1(0.1 \%)^{\dagger}$ & 0 & - & - & - \\
\hline Peripheral artery disease & $3(0.2 \%)^{\dagger}$ & 0 & - & - & - \\
\hline Symptomatic & $937(53 \%)^{\dagger}$ & $193(72 \%)^{\ddagger}$ & 2.3 & $1.7-3.0$ & $<0.05$ \\
\hline
\end{tabular}

CEAP, clinical, aetiological, anatomical and pathological elements; OR, odds ratio; $95 \% \mathrm{Cl}$ OR, confidence intervals $95 \%$ for odds ratio; NS, not statistically significant

*Representative percentage of the total cases (2036)

${ }^{\dagger}$ Representative percentage of the total cases of CEAP $\left(C_{1}-C_{3}\right)=1768$

${ }^{\ddagger}$ Representative percentage of the total cases of CEAP $\left(C_{4}-C_{6}\right)=268$

§Reference category 
reflux patterns were correlated to the two established clinical categories, mild to moderate CVI and severe CVI. Taking as a reference category the isolated SVS pattern, no statistical significant differences were found. However, a marginal nonstatistical significance (OR 3.02; $P=0.07$ ) was observed, with an increase in the probability to be in the severe CVI group if the reflux pattern involved the three venous systems without segment 10 (pelvic) being the cause of the reflux in the DVS. The same analysis was carried out with the subgroup of symptomatic patients, but there was no statistically significant association.

\section{Superficial venous system}

All possible reflux patterns were analysed according to the different combinations of the three variables considered within the SVS. Table 3 shows all the different isolated reflux patterns within the SVS that had at least a frequency greater than 30 cases. These reflux patterns were analysed relative to the CEAP clinical severity (Table 3), keeping as the reference the least severe non-saphenous reflux pattern.

GSV involvement above and below the knee increases significantly the probability of being in the $\mathrm{C}_{4}-\mathrm{C}_{6}$ CEAP category with or without SSV involvement. Although no statistical significance was found, the isolated reflux from the AAGSV segment had a tendency to be associated with mild to moderate CVI (OR=2.7; $P=0.06)$. When these reflux patterns were analysed in the subgroup of symptomatic patients, it was observed that the isolated AAGSV reflux pattern increased the probability of belonging to the mild to moderate CVI 12.5 times $(\mathrm{OR}=12.5 ; P=$ $0.003)$.

\section{Reflux pattern according to the venous reflux point}

\section{Reflux in the groin}

The SFJ reflux of GSV was chosen as a reference category according to the statistical criterion due to the presence of a greater number of cases. Using this reference, the remaining types of reflux in the groin presented themselves as variables associated with mild to moderate CVI (Table 4). In the subgroup of symptomatic patients, these types of reflux behaved in a similar manner, with the exception of the competent SFJ of the AAGSV with reflux from proximal veins, which did not present statistically significant differences.

\section{Reflux in the popliteal fossa}

The reference category chosen was the SPJ reflux according to the statistical criterion for the presence of a greater number of cases. There were no statistically significant associations found overall, nor in the subgroup of symptomatic patients.

\section{Reflux in the PV system}

Cases where the origin of the VVs stemmed from the group of PVs in the gluteal and the thigh were grouped together on one side, and the group of PVs of the knee + leg + ankle and foot on another. When using as reference category the group of PVs of the gluteal + thigh, there were no associations observed nor tendencies to any of the two clinical categories studied. These findings were the same in the subgroup of symptomatic patients.

\section{Pure non-saphenous reflux}

Nearly all the 'pure' non-saphenous refluxes belonged to the mild to moderate CVI 156/162

Table 3 Relationships of the reflux patterns in the superficial venous system with the symptomatology and as a function of the clinical severity

\begin{tabular}{|c|c|c|c|c|c|}
\hline Patterns of venous reflux & $\operatorname{CEAP}\left(\mathrm{C}_{1}-\mathrm{C}_{3}\right)(\%)^{*}$ & $\operatorname{CEAP}\left(\mathrm{C}_{4}-\mathrm{C}_{6}\right)(\%)^{*}$ & OR & $95 \% \mathrm{Cl}$ OR & $P$ value \\
\hline Telangiectases/reticular veins & $6(100 \%)$ & 0 & - & & \\
\hline GSV & $468(85.7 \%)$ & $78(14.3 \%)$ & 1.59 & $0.97-2.62$ & NS \\
\hline GSV & $17(77.3 \%)$ & $5(22.7 \%)$ & 2.54 & $1.03-6.21$ & $<0.05$ \\
\hline SSV & $122(90.4 \%)$ & $13(9.6 \%)$ & 1.07 & $0.54-2.14$ & NS \\
\hline AAGSV & $118(96.7 \%)$ & $4(3.3 \%)$ & 0.36 & $0.12-1.06$ & NS \\
\hline Non-saphenous ${ }^{\dagger}$ & $173(91.0 \%)$ & $17(9.0 \%)$ & $1^{\dagger}$ & & \\
\hline GSV + SSV & $35(92.1 \%)$ & $3(7.9 \%)$ & 0.88 & $0.27-2.86$ & NS \\
\hline GSV + SSV & $64(83.1 \%)$ & $13(16.9 \%)$ & 1.88 & $0.96-3.69$ & NS \\
\hline GSV + GSV & $472(84.6 \%)$ & $86(15.4 \%)$ & 1.72 & $1.05-2.82$ & $<0.05$ \\
\hline GSV + GSV + SSV & $52(76.5 \%)$ & $16(23.5 \%)$ & 2.62 & $1.40-4.90$ & $<0.05$ \\
\hline
\end{tabular}

CEAP, clinical, aetiological, anatomical and pathological elements; GSV , great saphenous vein above the knee; GSV , great saphenous vein below the knee; SSV, small saphenous vein; AAGSV, anterior accessory great saphenous vein; OR, odds ratio; $95 \% \mathrm{Cl} O \mathrm{R}$, confidence intervals $95 \%$ for odds ratio; NS, not statistically significant

*Representative percentage within the reflux pattern

${ }^{\dagger}$ Reference category 
Table 4 Frequency and relationship of the refluxes in the groin with the CEAP clinical severity

\begin{tabular}{|c|c|c|c|c|c|c|}
\hline Reflux in the groin & Cases (\%)* & $\operatorname{CEAP}\left(\mathrm{C}_{1}-\mathrm{C}_{3}\right)(\%)^{\dagger}$ & $\operatorname{CEAP}\left(\mathrm{C}_{4}-\mathrm{C}_{6}\right)(\%)^{\dagger}$ & OR & $95 \% \mathrm{Cl}$ OR & $P$ value \\
\hline SFJ reflux of the GSV & 655 (32.2\%) & $508(77.6 \%)$ & $147(22.4 \%)$ & $1^{\neq}$ & & \\
\hline $\begin{array}{l}\text { Competent SFJ of the GSV with } \\
\text { reflux from proximal veins }\end{array}$ & $629(30.9 \%)$ & 575 (91.4\%) & $54(8.6 \%)$ & 0.38 & $0.28-0.51$ & $<0.05$ \\
\hline SFJ reflux of the AAGSV & $70(3.4 \%)$ & $63(90 \%)$ & $7(10 \%)$ & 0.44 & $0.21-0.91$ & $<0.05$ \\
\hline Segmental reflux in AAGSV & $72(3.5 \%)$ & $68(94.4 \%)$ & $4(5.6 \%)$ & 0.24 & $0.09-0.64$ & $<0.05$ \\
\hline $\begin{array}{l}\text { Competent SFJ of the AAGSV with } \\
\text { reflux from proximal veins }\end{array}$ & $53(2.6 \%)$ & $48(90.6 \%)$ & $5(9.4 \%)$ & 0.42 & $0.18-0.97$ & $<0.05$ \\
\hline
\end{tabular}

CEAP, clinical, aetiological, anatomical and pathological elements; AAGSV, anterior accessory great saphenous vein; SFJ, saphenofemoral junction; GSV, great saphenous vein; OR, odds ratio; $95 \% \mathrm{Cl} O \mathrm{OR}$, confidence intervals $95 \%$ for odds ratio; NS, not statistically significant

*Representative percentage of the total cases (2036)

${ }^{\dagger}$ Representative percentage within the reflux pattern

${ }^{\ddagger}$ Reference category

(96.3\%). Similar results were found among symptomatic patients who presented this reflux pattern.

Finally, by using bivariate analysis, all possible venous reflux points observed and the CEAP $\left(\mathrm{C}_{4}-\right.$
$\mathrm{C}_{6}$ ) variables were analysed (Table 5). The following variables were excluded from the analysis due to the insufficient number of cases in the CEAP $\left(\mathrm{C}_{4}-\right.$ $\mathrm{C}_{6}$ ) category: SSV reflux through an incompetent

Table 5 Association of the all possible venous reflux points of the limb and the most severe clinical form of CVI (CEAP C4-C6)

\begin{tabular}{|c|c|c|c|c|}
\hline Venous reflux point & CEAP $\mathrm{C}_{4}-\mathrm{C}_{6}$ & OR & $95 \% \mathrm{Cl} \mathrm{OR}$ & $P$ value \\
\hline \multicolumn{5}{|l|}{ SFJ reflux of GSV } \\
\hline Yes & $152 / 692(22 \%)$ & 2.96 & $2.28-3.84$ & $<0.05$ \\
\hline No & $116 / 1335(8.7 \%)$ & & & \\
\hline \multicolumn{5}{|c|}{ Competent SFJ of the GSV with reflux from pelvis } \\
\hline Yes & $54 / 643(8.4 \%)$ & 0.50 & $0.37-0.69$ & $<0.05$ \\
\hline No & $214 / 1384(15.5 \%)$ & & & \\
\hline \multicolumn{5}{|c|}{ Competent SFJ of the GSV with reflux from epigastric vein } \\
\hline $\begin{array}{l}\text { Yes } \\
\text { No }\end{array}$ & $\begin{array}{c}2 / 25(1.8 \%) \\
266 / 2002(13.3 \%)\end{array}$ & 0.57 & $0.13-2.42$ & NS \\
\hline \multicolumn{5}{|l|}{ SFJ reflux of AAGSV } \\
\hline Yes & $11 / 87(12.6 \%)$ & 0.95 & $0.50-1.81$ & NS \\
\hline No & $257 / 1940(13.2 \%)$ & & & \\
\hline \multicolumn{5}{|c|}{ Competent SFJ of the AAGSV with reflux from pelvis } \\
\hline Yes & $6 / 59(10.2 \%)$ & 0.74 & $0.31-1.73$ & NS \\
\hline No & $262 / 1968$ (13.3\%) & & & \\
\hline \multicolumn{5}{|c|}{ Segmental reflux in AAGSV } \\
\hline Yes & $4 / 72(5.6 \%)$ & 0.38 & $0.14-1.04$ & NS \\
\hline \multirow{2}{*}{\multicolumn{5}{|c|}{ SPJ reflux }} \\
\hline & & & & \\
\hline Yes & $24 / 208(11.5 \%)$ & 0.84 & $0.54-1.32$ & NS \\
\hline No & $244 / 1819(13.4 \%)$ & & & \\
\hline \multicolumn{5}{|c|}{ SSV reflux though Giacomini vein } \\
\hline Yes & $2 / 12(16.7 \%)$ & 1.32 & $0.29-6.03$ & NS \\
\hline No & $266 / 2015$ (13.2\%) & & & \\
\hline \multicolumn{5}{|c|}{ Pure non-saphenous reflux } \\
\hline Yes & $6 / 159(3.8 \%)$ & 0.24 & $0.11-0.55$ & $<0.05$ \\
\hline No & $262 / 1868(14.0 \%)$ & & & \\
\hline \multicolumn{5}{|l|}{ PV gluteal $+P V$ thigh } \\
\hline Yes & $18 / 146(12.3 \%)$ & 0.92 & $0.55-1.53$ & NS \\
\hline No & $250 / 1881(13.3 \%)$ & & & \\
\hline \multicolumn{5}{|c|}{$\mathrm{PV}$ knee $+\mathrm{PV}$ calf $+\mathrm{PV}$ ankle $+\mathrm{PV}$ foot } \\
\hline Yes & $9 / 82(11.0 \%)$ & 0.80 & $0.40-1.62$ & NS \\
\hline No & $259 / 1945(13.3 \%)$ & & & \\
\hline
\end{tabular}

CEAP, clinical, aetiological, anatomical and pathological elements; AAGSV, anterior accessory great saphenous vein; SFJ, saphenofemoral junction; GSV, great saphenous vein; SPJ, saphenopopliteal junction; SSV, small saphenous vein; PV, perforating venous system; OR, odds ratio; $95 \% \mathrm{Cl}$ OR, confidence intervals $95 \%$ for odds ratio; NS, not statistically significant $\mathrm{No}=$ reference category 
VV, SSV reflux through gastrocnemius veins and competent SFJ of AAGSV with reflux from the epigastric vein. SFJ reflux of the GSV was associated with severe CVI (OR=2.96; CI 95\%: 2.2-3.8), whereas competent SFJ of the GSV with reflux from proximal veins $(\mathrm{OR}=2$; $\mathrm{CI} 95 \%$ : 1.4-2.7) and the pure non-saphenous reflux $(\mathrm{OR}=4.1 ; \mathrm{CI}$ 95\%: $1.8-9.0)$ were associated with mild to moderate $\mathrm{CVI}\left(\mathrm{C}_{1}-\mathrm{C}_{3}\right)$.

\section{Discussion}

\section{Risk factors and concurrent diseases}

Obesity has presented as the variable that to a greater extent increases the risk of suffering from a more severe CVI. Padberg et al. ${ }^{15}$ reported that morbid obesity type III should be considered the greatest factor contributing to severe CVI, regardless of whether or not it has a venous origin. Symptomatic patients were found 2.3 times more often in the severe CVI group than in the mild to moderate CVI group. On the other hand, in a recent study, patients who had a more severe CVI communicated fewer symptoms than those with non-complicated VVs. ${ }^{16}$ But in this study, which did not include the more severe clinical class $\left(C_{6}\right)$, symptomatology severity was evaluated alone, in such a way that, for example, the degree of pain or weight of the extremities in the lower clinical classes $\left(C_{2}-C_{3}\right)$ was much higher than in the $\mathrm{C}_{4}-\mathrm{C}_{5}$ clinical classes. The authors justified this unexpected finding by only evaluating the symptoms and their tendency to influence a great array of confusing factors.

Boivin et al. argue that pregnancy may act as a risk factor for the development of VVs in predisposed women. ${ }^{17}$ Also, Sparey et al. found that normal veins, in spite of changes in venous diameter during pregnancy comparable with that seen in those with pre-existing venous disease, return to normal after delivery, but some VVs deteriorate during pregnancy, and this may be progressive with successive pregnancies. ${ }^{18}$ Previously, Cornu-Thenard et al. had already observed a correlation between the total number of pregnancies and the size of VVs. ${ }^{19}$ In our study, $60 \%$ of women had a history of pregnancy; however, their presence was associated with mild to moderate CVI $\left(\mathrm{C}_{1}-\mathrm{C}_{3}\right)$.

Similar to other authors, ${ }^{20-22}$ two clinical categories have been differentiated in our study. The distribution of cases in both categories, mild to moderate CVI in $86.8 \%$ and severe CVI in $13.2 \%$, is similar to that found by Bradbury et al.' $\mathrm{s}^{21}$ study of 428 patients, where CVI was evident during a DU, $84.8 \%$ reported mild to moderate CVI and $15.2 \%$ reported severe CVI. The most frequent clinical class $(97.7 \%)$ was that of the VVs (C2); along with the $\mathrm{C} 1$ class, telangiectasias and reticular veins, without the co-existence of the rest of the clinical classes, were found in $75.8 \%$. Characteristic symptoms of CVI were present in $55 \%$ and keeping in mind that $75.5 \%$ of the population were women, it seems obvious that aesthetics was a most likely reason for the initial vascular surgery consultation in these patients.

\section{Reflux pattern according to the anatomy of the CEAP classification}

We have observed that when reflux was present in the GSV segments above and below the knee, there was a greater probability that the patient would be in the CEAP $\mathrm{C}_{4}-\mathrm{C}_{6}$ category, and when the reflux in the SSV segment was added to this combination, the likelihood of having a more severe clinical level increased 2.6 times. Some studies $^{23,24}$ agree with the fact that the greater the anatomical extension of the reflux, the higher the increase in incidence of symptoms and signs. Labropoulos et al..$^{25}$ observed that the reflux along the entire GSV is more likely to produce symptoms and signs from the CVI. Nevertheless, Danielsson et al. ${ }^{20}$ found that the reflux of the GSV above and below the knee (axial reflux) did not increase the prevalence of tissue change as compared with superficial segmentary insufficiency. Some authors have indicated that the reflux confined to segments below the knee increased the clinical severity more than the refluxes found above the knee, demonstrating their importance for determining normal venous function. ${ }^{25,26}$ Like us, in a previous study, isolated reflux in the SSV was associated with a wide range of severity; however, classes 5 and 6 were uncommon. ${ }^{27}$ Lin et al. ${ }^{22}$ affirm that reflux in the SSV is more common in patients with more severe CVI, but clarify that they are not able to establish whether the reflux in the SSV is a sign of the increase in the severity of the CVI or part of the global reflux present in the inferior extremities, with more severe affectation of the CVI.

In relation to the AAGSV, we found a tendency to be associated with mild to moderate CVI. It has been shown that although the whole clinical spectrum of the CVI has been observed, reflux of the AAGSV has been more frequently found in the clinical phases without tissue lesions. ${ }^{28,29}$ Reflux in the AAGSV's venous system habitually 
determines VVs limited to the anterior and lateral surface of the thigh. As previously mentioned, the extended segments of the reflux would be associated with tissue lesion while it would not be observed in the shorter segments of reflux.

\section{Reflux pattern according to the venous reflux point}

Among the groin refluxes, with respect to the reference category SFJ reflux of the GSV, all other refluxes were associated with the mild to moderate CVI. The association of the competent SFJ with reflux from proximal veins to the mild to moderate CVI, when a competent terminal valve, could be the result of a proportion of these veins draining into the deep venous system by means of the competent SFJ. ${ }^{30}$ Barros et al. demonstrated by air plethysmography that patients with ostial GSV insufficiency had a great amount of reflux compared with those with no ostial insufficiency. ${ }^{31}$

Some authors have defined as non-saphenous reflux those VVs that are not part of GSV or SSV systems. ${ }^{17,32}$ Therefore, they include reflux from perineal and PV systems. From our point of view, they should differentiate. Pelvic origin reflux would be an entity predominantly observed in women due to a sex-specific mechanism of aetiol$\mathrm{ogy}^{32}$ which has little resemblance, for example, to a PV reflux in the popliteal fossa.

From an anatomical and haemodynamic point of view, we tried to carry out a stratification of clinical severity as a function of all possible proximal locations of the reflux of varicose pathology. Once again, SFJ reflux of the GSV displayed a statistically significant association to the more severe disease category, while the competent SFJ of the GSV with reflux from the pelvis was associated with mild to moderate CVI. Pittaluga et al. reported that greater reflux extension is accompanied by a more advanced clinical stage, and like us, the presence of a reflux at the junction appeared to be determined ('a key point') since the rate of trophic changes rose from $1.3 \%$ to $9.8 \%$ when the junction is refluxing. ${ }^{33}$

In different studies, it has been observed that age increases the risk of suffering skin lesions attributed to venous pathology in both sexes. ${ }^{34,35}$ However, it is possible that, more than the ageing process itself, the venous pathology was already present at an earlier age and it could have been acting in a prolonged manner over time and therefore determining those skin changes. We lack information regarding the time elapsed from the initial detection of an SFJ reflux of the GSV to the onset of these tissue lesions. But if we had a patient with VVs without tissue lesions, which displayed an SFJ reflux of the GSV, we believe that in this situation early corrective surgery would be the most beneficial intervention. However, the study limitation is its retrospective and transversal design, and therefore we are not able to draw conclusions about the clinical evolution of the different reflux patterns.

\section{Conclusion}

We have shown that in patients with VVs, those with ostial valve incompetence of the GSV show a greater association with a more severe clinical category of CVI than other possible venous points of reflux. The anatomical and haemodynamic studies using DU is a useful diagnostic tool that allows, by identifying the pattern of reflux of varicose pathology, characterization of the probable association to CVI clinical severity and thus rationalizes the best treatment possible.

\section{Acknowledgements}

Special thanks to Dr Isabel García Gimeno and Dr Jose Manuel Rodriguez Paz for their help in editing the manuscript.

\section{References}

1 Wong J, Duncan J, Nichols D. Whole-leg duplex mapping for varicose veins: observations on patterns of reflux in recurrent and primary legs, with clinical correlation. Eur J Vasc Endovasc Surg 2003;25:267-75

2 Jutley R, Cadle I, Cross K. Preoperative assessment of primary varicose veins: a duplex study of venous incompetence. Eur J Vasc Endovasc Surg 2001;21:370-3

3 Singh S, Lees TA, Donlon M, Harris N, Beard JD. Improving the preoperative assessment of varicose veins. Br J Surg 1997;84:801-2

4 Blomgren L, Johansson G, Bergquist D. Randomized clinical trial of routine preoperative duplex imaging before varicose vein surgery. Br J Surg 2005;92:688-94

5 Coleridge-Smith P, Labropoulos N, Partsch H, Myers K, Nicolaides A, Cavezzi A. Duplex ultrasound investigation of the veins in chronic venous disease of the lower limbs - UIP consensus document. Part I. Basic principles. Eur J Vasc Endovasc Surg 2006;31:83-92

6 Cavezzi A, Labropoulos N, Partsch H, et al. Duplex ultrasound investigation of the veins in chronic venous disease of the lower limbs - UIP consensus document. Part II. Anatomy. Eur J Vasc Endovasc Surg 2006;31: 288-99 
7 Nicolaides A. Investigation of chronic venous insufficiency. A consensus statement. Circulation 2000;102: e126-e163

8 García-Gimeno M, Rodríguez Camarero S, Tagarro Villalba $S$, et al. Duplex mapping of 2036 primary varicose veins. J Vasc Surg 2009;49:681-9

9 Juan-Samsó J, Fontcuberta-García J, Senin-Fernández M, Vila-Coll R. Guía básica para el diagnóstico no invasivo de la insuficiencia venosa. Angiología 2002;54:44-56. (free available in http://www.revangiol.com)

10 Kalodiki E, Calahoras L, Nicolaides A. Make it easy: duplex examination of the venous system. Phlebology 1993;8:17-21

11 Min R, Khilnani N, Golia P. Duplex ultrasound evaluation of lower extremity venous insufficieny. J Vasc Interv Radiol 2003;10:1233-41

12 Porter J, Moneta $G$ and an Internacional Consensus Committee on Chronic Venous Disease. Reporting standards in venous disease: an update. J Vasc Surg 1995;21: 635-45

13 Escribano JM, Juan J, Bofia R, et al. Haemodynamic strategy for treatment of diastolic anterograde Giacomini varicose veins. Eur J Vasc Endovasc Surg 2005;30:96-101

14 Caggiati A, Bergan J, Gloviczki P, Jantet G, WendellSmith C, Partsch H. Nomenclature of the veins of the lower limbs: an international interdisciplinary consensus statementt. J Vasc Surg 2002;36:416-22

15 Padberg F, Cerveira J, Brajesh L, Pappas P, Varma S, Hobson II R. Does severe venous insufficiency have a different etiology in the morbidly obese? Is it venous?. J Vasc Surg 2003;37:79-85

16 Howlader M, Coleridge-Smith P. Symptoms of chronic venous disease and association with systemic inflammatory markers. J Vasc Surg 2003;38:950-4

17 Boivin P, Cornu-Thenard A, Charpak Y. Pregnancyinduced changes in lower extremity superficial veins:An ultrasound scan study. J Vasc Surg 2000;32: $570-4$

18 Sparey N, Hadad N, Sissons G, Rosser S, de Cossart L. The effect of pregnancy on the lower limb venous system of women with varicose veins. Eur J Vasc Endovasc Surg 1999;18:294-9

19 Cornu-Thenard A, Boivin P, Baud JM, De Vincenzi I, Carpentier P. Importance of the familial factor in varicose disease. J Dermatol Surg Oncol 1994;20:318-26

20 Danielsson G, Eklof B, Grandinetti A, Lurie F, Kistner R. Deep axial reflux, an important contributor to skin changes or ulcer in chronic venous disease. J Vasc Surg 2003;38:1336-41

21 Bradbury A, Evans C, Allan P, Lee A, Ruckely V, Fowkes F. The relationship between lower limb symptoms and superficial and deep venous reflux on duplex ultrasonography The Edinburgh Vein Study. J Vasc Surg 2000;32: $921-31$
22 Lin J, Iafrati M, O’Donnell T, Estes J, Mackey W. Correlation of duplex ultrasound scanning-derived valve closure time and clinical classification in patients with small saphenous vein reflux: is lesser saphenous vein truly lesser?. J Vasc Surg 2004;39:1053-58

23 Labropoulos N, Delis K, Nicolaides A, Leon M, Ramaswami G, Volteas N. The role of the distribution and anatomic extent of reflux in the development of signs and symptoms in chronic venous insufficiency. J Vasc Surg 1996;23:504-10

24 Seidel A, Miranda F, Juliano Y, Novo N, dos Santos N, de Souza D. Prevalence of varicose veins and venous anatomy in patients without truncal saphenous reflux. Eur J Vasc Endovasc Surg 2004;28:387-90

25 Labropoulos N, Leon M, Nicolaides A, Giannoukas A, Volteas N, Chan P. Superficial venous insufficiency: correlation of anatomic extent of reflux with clinical symptoms and signs. J Vasc Surg 1994;20:953-8

26 Hanrahan L, Araki C, Rodriguez A, Kechejian G, LaMorte W, Menzoian J. Distribution of valvular incompetence in patients with venous stasis ulceration. J Vasc Surg 1991;13:805-12

27 Labropoulos N, Giannoukas A, Delis K, et al. The impact of isolated lesser saphenous vein system incompetence on clinical signs and symptoms of chronic venous disease. J Vasc Surg 2000;32:954-60

28 Labropoulos N, Leon L, Amaral S, et al. Sapheno-femoral junction reflux in patients with a normal saphenous trunk. Eur J Vasc Endovasc Surg 2004;28:595-9

29 Labropoulos N, Kang S, Mansour A, Giannoukas A, Buckman J, Baker W. Primary superficial vein reflux with competent saphenous trunk. Eur J Vasc Endovasc Surg 1999;18:201-6

30 Jiang P, van Rij A, Christie R, Hill G, Thomson I. Nonsaphenofemoral venous reflux in the groin in patients with varicose veins. Eur J Vasc Endovasc Surg 2001;21: $550-7$

31 Barros M, Labropoulos N, Ribeiro A, Okawa R, Machado F. Clinical significance of ostial great saphenous vein reflux. Eur J Vasc Endovasc Surg 2006;31:320-4

32 Labropoulos N, Tiongson J, Tassiopoulos A, Kang S, Mansour A, Baker W. Nonsaphenous superficial vein reflux. J Vasc Surg 2001;34:872-7

33 Pittaluga P, Chastanet S, Rea B, Barbe R. Classification of saphenous refluxes: implications for treatment. Phlebology 2008;23:2-9

34 Evans C, Fowkes F, Ruckely V, Lee A. Prevalence of varicose veins and chronic venous insufficiency in men and women in the general population:Edinburgh Vein Study. J Epidemiol Community Health 1999;53:149-53

35 Carpentier P, Maricq H, Biro C, Poncot-Makinen C. Prevalence, risk factors, and clinical patterns of chronic venous disorders of lower limbs: A population-based study in France. J Vasc Surg 2004;40:650-9 